\title{
Correction to: Factors associated with changes in volumetric bone mineral density and cortical area in men with ankylosing spondylitis: a 5-year prospective study using HRpQCT.
}

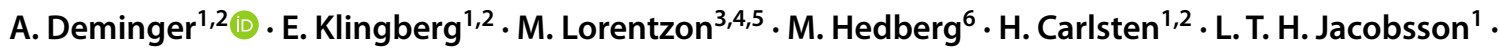 \\ H. Forsbladd'Elia ${ }^{1,2,7}$
}

Published online: 2 November 2021

(c) The Author(s) 2021

\section{Correction to: Osteoporosis International} https://doi.org/10.1007/s00198-021-06049-4

The original version of this article, published on 14 July 2021, unfortunately contained a mistake.

The title of the PDF version of the article unfortunately contains an error due to a typesetting mistake.

The publisher apologizes for this mistake.

The original article has been corrected.

Open Access This article is licensed under a Creative Commons Attribution 4.0 International License, which permits use, sharing, adaptation, distribution and reproduction in any medium or format, as long as you give appropriate credit to the original author(s) and the

The original article can be found online at https://doi.org/10.1007/ s00198-021-06049-4.

\footnotetext{
A. Deminger

anna.deminger@vgregion.se

1 Department of Rheumatology and Inflammation Research, Institute of Medicine, Sahlgrenska Academy, University of Gothenburg, Box 480, 40530 Gothenburg, Sweden
}

2 Department of Rheumatology, Region Västra Götaland, Sahlgrenska University Hospital, 41345 Gothenburg, Sweden

3 Geriatric Medicine, Institute of Medicine, Sahlgrenska Academy, University of Gothenburg, Gothenburg, Sweden

4 Geriatric Medicine Clinic, Region Västra Götaland, Sahlgrenska University Hospital, Gothenburg, Sweden

5 Mary McKillop Institute for Health Research, Australian Catholic University, Melbourne, Australia

6 Section of Rheumatology, Region Västra Götaland, Södra Älvsborg Hospital, Borås, Sweden

7 Department of Public Health and Clinical Medicine, Rheumatology, Umeå University, Umeå, Sweden source, provide a link to the Creative Commons licence, and indicate if changes were made. The images or other third party material in this article are included in the article's Creative Commons licence, unless indicated otherwise in a credit line to the material. If material is not included in the article's Creative Commons licence and your intended use is not permitted by statutory regulation or exceeds the permitted use, you will need to obtain permission directly from the copyright holder. To view a copy of this licence, visit http://creativecommons. org/licenses/by/4.0/.

Publisher's note Springer Nature remains neutral with regard to jurisdictional claims in published maps and institutional affiliations. 